\title{
Nanogram per Well
}

National Cancer Institute

\section{Source}

National Cancer Institute. Nanogram per Well. NCI Thesaurus. Code C73766.

A unit of mass concentration expressed in nanogram(s) per plate well. 